\title{
Personal Aesthetic Values Development as the Basis for a Modern Musician's Spiritual Formation
}

Natalia Anufrieva

Eugeny Anufriev

Irina Korsakova

Irina Slutskaya

\section{Anna Shcherbakova}

Russian State Social University, Wilhelm Pieck str., 4, Moscow, 129226, Russia

\section{Doi:10.5901/mjss.2015.v6n5s1p569}

\begin{abstract}
This article proves the necessity of personal aesthetic foundations development, proposes mechanisms for the formation of aesthetic values, studies the "aesthetic" category in the aspect of the problem of the individual's spiritual world formation. Musical activity is considered as a basis for the development of aesthetic consciousness and the most important factor in the formation of aesthetic culture of the modern musician. In Methods section, a four-complex model of individual's spiritual selfdetermination and self-actualization is provided.
\end{abstract}

Keywords: musical art, personal spiritual world, musical culture, aesthetic values, aesthetic consciousness, aesthetic activity, higher professional musical education, humanism, creativity.

\section{Introduction}

Transformation of the personal spiritual world in the social crisis appears as a complex multi-faceted task. Aesthetic consciousness directly influences the essence of man, since it has a specific property to transfer perceived outside world in the facts of inner awareness through emotional and aesthetic experience. As a result, folding aesthetic ideas determine the principles, tinge, and quality originality of all human activities on the development of the world.

Aesthetic consciousness development is not only a reflection of individual's existing aesthetic qualities and his relationship to the world, but it also determines their content and manifestation. Without the formation of ideas about the perfect, ideal, it is impossible both harmonious interaction with the world, and the true creative self-realization. The aesthetic development of human brings together all the essential qualities of a man; without it is impossible both realization of his intellectual abilities, and the formation of moral principles. Aesthetically developed person acts as the goal, mean and the highest value of society.

Comprehension of the phenomenon of musical art is "a thorny path to Beauty" (L. Shaposhnikova) affecting the very essence of man, his spirit that "it gives the ability to create the most important thing in his life - the culture, the existence of which is impossible without beauty" (Shaposhnikova, 1999). As the great Russian philosopher Pavel Florensky said "Beauty is the Beauty, it is Life, Creativity, Reality" (Florensky, 1993). The ability to see, understand and create the Beauty is the basis of deep comprehension of life through art, "any new aesthetic reality clarifies an ethical reality for a man. For aesthetics is the mother of ethics; the concepts of "good" and "bad" are the concepts that are primarily aesthetic, anticipating the categories of "good" and "evil" (Brodsky, 1991).

\section{Methods}

The study of complex mechanisms' influence on the formation of the personal aesthetic values allows us to represent it in the form of an universal integrated model of the phase, purposeful movement for spiritual self-determination and selfactualization of the individual.

The first stage is classified as emotional and motivational. At this stage, an emotional response is necessary to be 
ensured, which is seen as a prerequisite to the formation of the personal aesthetic values. At this stage, mechanism of experiences is necessary to actively "work", which is the "trigger" that makes experienced emotions to cause the need to communicate with one or another humanitarian text, with the works of a philosopher or a poet, a writer or a musician, or start to feel the need to appeal to a particular religion. The main objective of this stage is a inclusion of a mechanism of empathy that causes a desire to "empathy" in the new apprehended world, creates the effect of resonance, string vibration of the soul that responds to the information. No less important task is the emergence of cognitive interest, which contributes to the appearance and the constant strengthening of motivation to action, to the manifestation of cognitive activity, the expansion of the information field. This is the stage where the gnostic potential of the individual "unfolds" in maximum, the horizons of knowledge expand, and the process of learning becomes a recognized necessity.

The second stage is the socio-cultural adaptation stage, that is an entrance into the world of aesthetic values. This is a very significant stage of value consciousness, evaluation of comprehended meanings and values. This is a stage, when personal attitude to them is formed, personal interpretation is given. This stage includes a maximum reveal of a personal axiological capacity. The second stage is characterized by doubts, the spiritual quests, the person seeks his/her own path in the space of culture, highlights those meanings and values that meet his/her inner needs, help make sense of his/her place in the emerging ideas about the world. At this stage, the mechanisms of empathy and associative links already actively function, this allows the person to feel the historical continuity in the cultural space, to realize himself as a part of this space, linking together the past, present and future. Mechanism of cognitive activity becomes a constant companion of the person, who discovers more and more new prospects in gaining of spiritual knowledge.

The third stage is the spiritual self-determination stage, when a person has a clear vision for how aesthetic ideals is going to follow, formulates a range of life goals and objectives. This stage includes the mechanisms of spiritual communication, intercourse, dialogue, when the mechanism of personal interpretation works flawlessly, clearly identifying those personal meanings and values, those aesthetic and ethical ideals that have become benchmarks for the construction of personal spiritual space. At this stage, a significant role is played by the mechanisms of creative activity, improvement and self-improvement, regulation and self-regulation.

This is the stage of maximum development of the creative, communicative and artistic potential of the individual, which allows him/her to confidently embark on path of creative implementation of hislher views, ideas and skills for implementing the mature aesthetic and ethical ideals. It is a testament to a spiritual maturity of the person, the occurrence of the fourth and final stage, which is the beginning of a person's independent creative way as an object of a sociocultural creation.

\section{Results}

The basic principles of the formation and development of spiritual and creative personality is methodologically grounded in the Concept of Education Development in the Field of Culture and Art in 2008-2015 (Russian Federation Government Decree, 2008). In particular, as part of professional musical and educational objectives of the high school, the following blocks are determined:

1. Professional and personal qualities of the future musician. This block contains the following personal characteristics of the musician: the need to experience the beautiful, elegant, graceful, sublime; the need for cognitive harmony, striving to penetrate the essence of things; the focus on the quality of his work, on working with the team and the business decision to educational problems; the striving to uphold his own opinion, which is useful for a common goal.

2. Professional knowledge in the field of emotional and communicative activity of the future musician. The content of this block includes the knowledge of the general principles and laws of musical training and education, the structure of professional musical activity and professional qualities necessary for musician.

3. Professional skills in the field of emotional and communicative activities of the future musician. Skills included in this block reflect communicative, affective, regulatory and reflective elements of a professional musician's behavior; the ability to maintain the stability of emotional resources, to define the boundaries of his own knowledge and skills, to find ways and means to solve artistic and communicative problems.

To solve these problems it is necessary to form a system of values, allowing the younger generation of musicians to navigate directly within the experienced here and now, which is defined as a socio-cultural space of the third millennium (Valeeva, Rybakova, 2014). Therefore, higher professional school training specialists in education, culture and art, identifies training graduates competitive in the labor market, having formed values and positive qualities, willingness to dialogicality interaction with cultural nations and ethnic groups of the region, the country, and others as the main objectives. We conclude that the main criterion for the quality of music students teaching is not only a high level of 
professional competence (Valeeva, Karimova, 2014), functional training to perform certain types of professional activity, but also the development of personal qualities that allow them to be adaptive, competitive, stating and achieving goals based on self-realization, self-education, developing themselves and their environment, having a tolerant attitude to the representatives of the various ethnic communities.

\section{Discussion}

Genuine personality culture requires focus on comprehension of all the wealth of the human mind, the human artistic creativity. The scope and effectiveness of contacts with the cultural artifacts, their aesthetic aftereffect determine the quality problem of consumption and assimilation of artistic cultural values, so their social effectiveness throws into sharp relief in the modern system of national professional education. This situation can be changed subject to identify the priority updates of professional music education in general.

The essence of modernization lies in identifying of innovative ways and means of development, values education paradigms on the material of domestic art, as the man of the future is always a man of the present, who is aware and able to resolve the problem of time, the development of his people and aware of his activities' value for the country's future.

The main parameters of the modernization of higher education are the content and form, space and time, activity and attitude, reflection, autonomy, rationality and spirituality. The basis of the principles of higher education reform includes the spiritual values of all culture types, humanism as a fundamental basis of education cultural and centric features, and professionalism (Kallimulin, 2014).

In his work devoted to the study and analysis of humanism as an ethical category, researcher V. Rybin reveals the etymology and semantics of the term, compares different approaches to its interpretation, identifies specific elements in presented formulations, this allows him to formulate three basic meanings of this concept:

1. "Humanism is a progressive movement (ideological and cultural movement) of the Renaissance, which is based on the following principles: a free all-round development of personality; release from spiritual domination of feudalism and Catholicism; turning to ancient philosophy, literature, art, and so on.

2. Humanism is a worldview (system of views, ideas), based on the following principles: a person is the highest value of society; a person's benefit is an essence (raison d'etre, content) of social relations; a person has the right to freedom, happiness, development and expression of his/her abilities; a person is a creative personality, a receptacle of a creative potential.

3. Humanism is the attitude to people that is characterized by sensitivity, respect, fairness, compassion, care, love and empathy. Humanity can be defined as the set of the following qualities (properties) of the person manifested in actions and attitude to other people, as follows: responsiveness, attention, mercy, benevolence, love, compassion" (Rybin, 2004).

For understanding the phenomenon of musical art, we must consider this term not only from an ethical but also aesthetic part, as aesthetic and ethical principles in the space of art are closely intertwined, influencing and stipulating each other.

"Aesthetic" in all its manifestations is integrated and universal. Aesthetic as perfect of its kind is seen in all forms and spheres of reality (the environment, the arts, human relations) and is understood as the fullness of the object being (perfection in every time and the endless striving for the ideal of the Beauty). Perfect covers beautiful as well, and the sublime, and the terrible, and the tragic. Aesthetically creative attitude to music also includes a set of image-associative and dial-communication links with other spheres of art and life; professional skills, mental personality traits are colored with aesthetic attitude to music, as well as general humanitarian culture (teacher-musician). Experts say that feature of aesthetics is that the "aesthetic attitude is universal, there is no any special "aesthetic technology", which could be taught, and because it is a form of outside-concept experience of reality, there is no "aesthetic knowledge" that could be referred to the students on the appropriate lessons... Aesthetic education cannot be considered as a special lesson in the curriculum" (Kagan, 1997).

With all the abundance of characteristics and definitions of aesthetic, the aesthetic is primarily emotional. Being a concentrated expression of the emotional potential of the individual, aesthetic emotions act as a regulatory source of human consciousness and activities and determine all the main characteristics. It should be emphasized that the emotional means not only sensual level of aesthetic consciousness, but also rational and logical (aesthetic emotions are "intelligent emotions", according to L. Vygotsky). In addition, the scope of aesthetic emotions includes phenomena of imagination, fantasy, intuition, i.e. things attributable to the sphere of the unconsciousness, preconsciousness, superconsciousness. 
Another essential feature of the aesthetic is imagery. The imagery problem derives its discussion in the research literature, articles of art experts, aestheticians, and philosophers. Some scholars believe that artistic thinking is exclusively figurative, while science is only the conceptual and logical scope of thinking. Today, these judgments seem to be too one-sided, because consciousness itself is dialectically contradictory unity of the various mechanisms and processes carried out at different levels, in various forms, get filled with a diverse mix of disparate elements.

The third component of the aesthetic world is creativity. Creative work is an essential component of the aesthetic developed person. Creative thinking and self-improvement striving are key factors of aesthetic consciousness formation, in which, the aesthetic ideal is a system forming factor. Ideal as sample, rate and the ultimate goal of development, that is a free manifesting itself amateur personality, always concentrates interpretation of people on people from different ages who declare their lives as an incarnation of goodness, justice, honor, dignity and beauty. "When doing good deeds becomes a habit, they said in ancient China, - goodness is born, and hence naturally comes to the wonderful wisdom and spiritual perfection!" (Ancient Chinese philosophy, 1973). The aesthetic as a special form of existence emerges as the most optimal implementation of the creative potential of the individual, its essential self-realization as a manifestation of its human destiny.

The most important factor in shaping of the aesthetic consciousness is art. Its influence is universal, it is addressed both to the senses and to the mind of man, his moral beliefs and worldviews. Art not only reflects the current reality, but also shapes the future, gives an idea of the proper, perfect, and possible (Davies, 2012). Through the ideal, the art forms the man as he should be. Researcher I. Slutskaya believes that "art is a unique instrument of culture by the means of which man reveals himself and, thus, expands his living space, complementing his real life experience with an illusory experience of life within an artistic reality" (Slutskaya, 2011).

Formation of aesthetic consciousness cannot be considered in isolation from practice, aesthetic consciousness is formed in the course of aesthetic activity. Artistic and aesthetic activity serves as the spiritual and practical activity, its product has characteristics, its products have the material and spiritual essence: deploying in an artistic work, they embody a complex ideal content.

Aesthetic activity is one of the components of aesthetic culture. Today, awareness of this category goes beyond the strictly artistic activities, as it is manifested in all the larger area of production (both components of the process and results of activities, motives, orientations, intentions, all its material and spiritual tools have aesthetic characteristics). Aesthetic characteristics of this activity are the reflection of the creative essence of the production in the diversity of its manifestations and forms. Aesthetic activities are bigger manifested in everyday life, in the aestheticization of the environment (from urban planning and landscape design to the interior and household items: furniture, clothing, jewelry, etc.). Aesthetic activity is an essential element of leisure, sports, entertainment, and is inherent in all forms of communication.

Aesthetic activity is a creative activity by nature. Being a special form of synthesis of the individual and social, the aesthetic is creation of the beautiful, which, in turn, serves for the humanization of the whole world and enriching the inner world of the creator, the personality of the creator.

The many facets of person's aesthetic interactions with the world form a special aesthetic environment in which man lives and which he himself creates and forms. It includes the presentation of the beautiful, the taste, the ideal. This is a special model of the world that a man builds for himself and on the basis of his aesthetic yardsticks and preferences, and which projects into the various forms of his existence and activities.

Considering the problem of musical performance, we should consider the essence of the "activity" concept, which was considered by the representatives of domestic psychological scientific school, such as L.S. Vygotsky, P.P. Blonsky, A.G. Kasprzhak, K.K. Kornilov, A.N. Leontiev, S.L. Rubinstein as "a specifically human, adjustable by consciousness "internal" (psychic) and "external" (motor) activity aimed at achieving consciously stated goal" (Kasprzhak, 1997).

In art, creative freedom plays an important role as the ability to put artistic experiments and simulate lifetime situations, not limiting with adopted frames of the dominant scientific theories or everyday conceptions of the world. Folk wisdom says: "If the creativity is given a freedom, the creator wakes up as the master." In art and creativity, the freedom is understood as "the ability to put artistic experiments and simulate lifetime situations, not limiting with adopted frames of the dominant scientific theories or everyday conceptions of the world" (The Music teacher's Companion, 2003).

Russian philosopher N.A. Berdyaev said: "Art does not tolerate coercion and orders from outside. Creative artist obeys only his inner voice... Art involves mission, a mission is a call, the call inside the personality from the superpersonal and to superpersonal" (Berdyaev, 1994). Stanislaw Jerzy Lec considered "the first law in the arts is the freedom of inspiration and creativity" (Lec, 2001), A.I. Scherbakova believes that "Art in general and music as one of the most amazing species, allow a person to discover the uniqueness of his inner world, to grasp the essence of human nature, to marvel at its immensity" (Shcherbakova, 2014). 
One of the main properties of the individual is the ability to respond emotionally to events in his life, to empathize, to experience joy and sorrow, elation, empathy, or, on the contrary, rejection.

Emotional response to a grasped literary text is the first step that needs to be done to take the path of formation of aesthetic and ethical ideals of the person. It is obvious that the mechanism of emotional response should be primarily aimed at the upbringing of the senses, which requires mandatory conversion of experiences arising in empathy, which leads to the birth of such feelings as compassion, love, sense of duty, etc.

Emotional response arising in the process of communicating with literary text ("tears over a fiction", Alexander Pushkin said) includes the following mechanism: the mechanism of aesthetic empathy forming ability of empathy in the experience of another person.

Here, the mechanism of empathy coupled with a mechanism of associative links, creates the conditions for the inclusion of the following mechanism, which is the valuable understanding and evaluation of the information received. As a result of these mechanisms inclusion, the senses are created that V.E. Druginyn subdivides into four types: moral, aesthetic, intellectual, and practical.

Thus, the mechanism of spiritual communication, the mechanism of communication and dialogue are included, which are perceived as an ethical ideal, as the key to self-identity and self-determination in the space of culture. However, the "inclusion" of the mechanism of spiritual communication to a great extent depends on the depth of aesthetic feelings as "the ability to see the beauty in nature, sensitivity to it are the premise of ethical relations" (Druginyn, 2003). We have been repeatedly mentioned on the role of the arts in this process. L.N. Tolstoy defined the role of it very precisely, for him; art is not a means of pleasure, the purpose of which is exclusively a phenomenon of beauty, but something much greater, a condition of life on earth. He justifies this by saying that "art is one of the means of communication between people ... Art activities are based on the fact that man, seeing or hearing impaired expression of the feelings of another person, is able to experience the same feeling experienced by a person expressing his feeling" (Tolstoy, 1997).

It is important to note once again that when the aesthetic experience becomes personal value when it reaches a high level of development, the range of feelings infinitely expands as mechanisms of creativity, self-development and selfimprovement switch to full power. Aspiration to high aesthetic and ethical ideals includes mechanisms of self-regulation and self-control. The man begins to "listen" and "peer" in the deep essence of his "Ego", tries to determine how provided picture is consistent with the aesthetic and ethical ideals, which he has formulated for himself as examples in the life and activity.

N.I. Anufrieva notes the role of folk music in the formation of the spiritual culture of personality that "assumes an embodiment of the aesthetic beginning, realization and transfer of the emotional estimated attitude to the validity, to all aesthetic in the nature and a society, helps to wake in the person the ability to perceive perfection and integrity of the form developing in time, finding an embodiment in all kinds of human activity" (Anufrieva, 2011).

Culture contains a considerable amount of material for inclusion of mechanism of cognitive interest. Appeal to the philosophical thought from antiquity to the present day, the age-old experience of mankind, enclosed in all the religions of the world, the variety of manifestations of the essential features of a person in the artistic culture of humanity ensure uninterrupted operation of the mechanism of cognitive interest, the mechanism facilitating the attainment of Knowledge, which in humanitarian socio-cultural environment is transformed into Knowledge-experience.

\section{Conclusion}

Summarizing the above analysis, the following mechanisms of aesthetic values of personality can be revealed: emotional response as a prerequisite for inclusion of the individual in the process of humanitarian culture understanding; mechanism of experiences, which is an indicator that experienced emotions are transformed into a certain feeling; mechanism of aesthetic empathy, that lets talk about that personality befalling humanitarian culture feels the need to communicate with a certain philosophical or literary text, tends to "empathy" in the world of another person; mechanism of empathy as an indicator of spiritual communication arising; mechanism of associative links, which allows to transfer the spiritual experience of the past in the present; mechanism of cognitive interest constantly expanding the creative horizons of the personality; mechanisms of spiritual communication, intercourse and dialogue as a new level of comprehension of art and culture, indicating a high level of achievement in the process of formation of the personal aesthetic ideals; mechanism of personal interpretation contributing to the attainment of personal meanings and values; mechanism of creative activity that allows you to embody established aesthetic ideals in life and work; mechanisms of improvement and self-improvement as a result of the conscious and purposeful creative activity; mechanisms of regulation and selfregulation, evidence of the spiritual and moral maturity of personality, embodying aesthetic and ethical ideals in his life and work; mechanisms for Knowledge and Belief, creating a holistic space in life and work that is required by creative 
spiritual person to implement the existing aesthetic and ethical ideals.

\section{References}

Ancient Chinese philosophy (1973). Comp. Texts in 2 volumes. Vol. 2. M.: Mysl, pp: 384.

Anufrieva, N. (2011). Musical Bilingualism of National Musical Instrumental Creativity. Philosophy of Music and Music Education As a Scientific Tendency. Collection of research articles: Part 2. Washington: Girshav Publishing Company USA; Moscow: Russian state social university, pp: 33-41.

Berdyaev, N.A. (1994). The meaning of creativity. Experience of human justify. Philosophy of creativity, culture and arts: 2 vol. Vol.1. M.: Iskusstvo, pp: 542.

Brodsky, I.A. (1991). Poems. Comp. Y. Gordin. Tallinn co-edition publishing "Eesti Raamat" and "Alexander", pp: 272.

Davies, Stephen (2012). Musical Understandings and Other Essays on the Philosophy of Music. Print publication date: 2011. Published to Oxford Scholarship Online: January 2012. DOI: 10.1093/acprof:0so/9780199608775.001.0001

Druginyn, V.E. (2003). Psychology of emotions, feelings and will. M.: Sphere, pp: 96.

Florensky, P.A. (1993). Iconostasis: Selected works of art. St. Petersburg: Mithril-Russian book, pp: 366.

Kagan, M.S. (1997). Aesthetics as a philosophical science. St. Petersburg: TOO TK "Petropolis", pp: 544.

Kallimulin A.M. (2014). Processes of reforming teacher training in modern russia (experience of the kazan federal university). American Journal of Applied Sciences. DOI : 10.3844/ajassp.2014.1365.1368. American Journal of Applied Sciences.Volume 11, Issue 8. Pages 1365-1368

Kasprzhak, A.G. (1997). New and innovative schools: the problems of today, prospects for the development and introduction to the collection. Innovative movement in the Russian school education. Ed. E. Dneprova, A. Kasprzhak and A. Pinsky. M.: Parsifal, pp: 416.

Lec, S.E. (2001). Unkempt thoughts. St. Petersburg: Crystal, pp: 173.

Russian Federation Government Decree (2008) "The Concept of the Education Development in the Field of Culture and Art in 20082015" of 25.08.2008 \#1244-p. Date Views 19.08.2014 http://www.artexplorer.ru.

Rybin, V.A. (2004). Humanism as an ethical category. M.: Logos, pp: 269.

Shaposhnikova, L.V. (1999). Thorny path of beauty. Art as a way of knowledge. Materials of the International Socio-Scientific Conference. M .: International Center of Roerich, pp: 304.

Shcherbakova, A.I. (2014). Philosophical understanding of music as a methodological basis of research in the field of musical art and education. Life Science Journal, 11(11): 429-432.

Slutskaya, I. (2011). Humanitarian Culture as a Component of Formation of Aesthetical and Ethical Ideals of Personality: A Problem Field of Research. Philosophy of Music and Music Education As a Scientific Tendency. Collection of research articles: Part 2. Washington: Girshav Publishing Company USA; Moscow: Russian state social university, pp: 62-74, 65.

The Music teacher's Companion (2003). Comp. TV Chelysheva. M.: Prosveschenie, pp: 238.

Tolstoy, L.N. (1997). Humane Pedagogy Anthology. M.: Publishing House of Shalva Amonashvili, pp: 221.

Valeeva, R.A. \& Karimova, L.Sh. (2014). Research of Future Pedagogue-Psychologists' Social Competency and Pedagogical Conditions of its Formation Procedia - Social and Behavioral Sciences (2014), pp. 40-44. DOI information: 10.1016/j.sbspro.2014.04.076.

Valeeva, R.A. \& Rybakova L.A (2014). The role of youth organization in the development of humanistic value orientations of higher educational institutions students. Procedia - Social and Behavioral Sciences (2014), pp. 817-821. DOI information: 10.1016/j. sbspro.2014.05.142. http://authors.elsevier.com/sd/article/S1877042814035666. 